\title{
Measuring Monsters, Academic Subjectivities, and Counting Practices
}

\author{
Susan O. Cannon \\ Mercer University
}

\section{Maureen Flint}

The University of Georgia

\section{DOI: https://doi.org/10.1344/inmr.v2i1.33375}

\section{Abstract}

In this paper, we explore the online academic research platforms we are entangled with as tenure-track faculty members in the neoliberal university. We are so embedded in these systems that the assumptions and constructions inherent in practices of counting are often lost, wrapped in the coils of counting practices-a becoming with algorithm. Though academic platforms are intricately enmeshed in our research and lives, they have been operating as "onto-epistemological blind spots" (Sweet et al., 2020 , p. 2). And yet, the numbers they produce and rely on (H-scores, impact factors, citation counts, and journal rankings) matter and are "promiscuous and inventive in [their] agential wanderings" (Barad, 2015, p. 487), offering possibilities for intimacy and response-ability to what we are and might become. In other words, attending to the monstrous qualities of counting practices offers an entry point for re-thinking the relational, ethical, and affective aspects of academic subjectivity. So, we attend to these qualities to become with the neoliberal counting and control mechanisms in innovative ways. Through this paper, we open ourselves to the wild possibilities of academic algorithms, working within and thinking with counting practices to intimately understand the ontologies of number at work in these platforms and how they work on our subjectivities. As we consider how our futures are being modelled and pre-empted, we think the algorithms in relation to feminist new materialist philosophers, Rosi Braidotti and Karen Barad. We ask: 'what if?' we were to think ontologies of number with these theories and see what possibilities emerge. We entangle Braidotti and 
Barad with Deleuzoguattarian philosophies to imagine different relational becomings; to construct new ways of attending to our monstrous potentials and possibilities.

\section{Keywords}

Measurement; algorithms; citational politics; counting; subjectivity; new materialisms

Congratulations, you reached a milestone.

... was your top paper this week.

Your weekly analytic snapshot...

... you were cited by an author from

A researcher is following your updates...

The cadence of these notifications is familiar to academics; email subject lines coerce clicks through mentions of citations, downloads, and reads. Clicks become data points that accumulate to $\mathrm{H}$-scores and numbers of views and mentions. Data points that, ultimately, are gathered together into counts and proffered to show that we deserve (or do not deserve) recognition as a legitimate academic subject. These are pseudoscientific refrains that both intoxicate and anaesthetise us in our homogeneous academic becoming (Guattari, 2000). Various counts accumulate to produce the academic body and perpetuate the appearance of difference all while desingularising and domesticating. In other words, counting practices and data points become mechanisms of a society of control (Deleuze, 1992). Counting is a boundary-drawing practice; a way of separating, sorting, and organising so that academics may be recognised as valued and individuated subjects. At the same time as counting practices are used to divide and separate, a new normal is also created through the collection of counts. Algorithms are used to model concepts such as impact and then produce numbers that represent an academic body's potential/past/future in the field. Though these models are intricately enmeshed in our research and lives, they have been operating as "onto-epistemological blind spots" (Sweet et al., 2019, p. 2) both 
blocking and distracting us from relational, ethical, and affective aspects of our lives and what we might be becoming.

With this paper we seek to make kin with the wild possibilities within academic platforms - to draw lines of inventive connection with ubiquitous contact zones while "cultivating response-ability" (Haraway, 2016, p. 104). To do so, we crawl along the undulations of counting practices in academia to work them and think them differently while asking:

1) How are academic platforms producing the concept of scholarly impact?

2) What assumptions, forms of content, and forms of expression do the platforms' information ontologies rely on?

3) How might thinking counting practices with feminist new materialisms offer different imagined futures for academics within the neoliberal academy?

In what follows, we first situate our inquiry in the theory and research on counting practices and algorithms. We explore how algorithms function in higher education and what they produce-particularly centring on the production of the neoliberal academic subject. We then offer Rosi Braidotti's (2006, 2013, and 2019) nomadic ethics and Karen Barad's (2007) specific material arrangements for knowledge-making apparatus as philosophical entry points to upturn the logics of counting practices. Guided by Braidotti and Barad, we turn to specific examples of counting practices, namely, the academic research platforms, ResearchGate, Academia, and Google Scholar. We explore the assumptions and logics of these platforms before imagining with Barad and Braidotti how we might enact our engagements with them differently and cultivate wild possibilities with/in the academy.

\section{Counting Practices, Algorithms, and the Neoliberal University}

As qualitative researchers, we share a history of complicating and opening up possibilities for knowledge productions rather than reifying stable definitions of 'good' teaching, assessment, or research (e.g., Cannella et al., 2015; Koro-Ljungberg, 2015; Roulston \& Bhattacharya, 2018; St. Pierre, 2014). The authors of this paper share a concern for the emerging and pervasive ways that academics are being counted and measured. In our current positions as tenure-track faculty engaged in the neoliberal 
academic marketplace, we often find our conversations circling and congealing around the ways we are counted. We fret over these counts as forecasting devices, scrying into our futures, Magic 8-Balls that continually respond 'reply hazy' and 'concentrate and ask again.' Our conversations have intensified and layered in the past several months as the global crisis of COVID-19 has heightened anxieties and drawn attention to counting practices. The role of algorithms in producing academic subjectivities is not simply located in the relations between academic bodies, publications, and citation scores. Rather, as the COVID-19 pandemic has also emphasised, algorithms spiral out to other counting mechanisms of university rankings and resource distribution, implicating the neoliberal production of the university itself. Specifically, the practice of ranking or stratifying universities is entangled with the practice of measuring faculty. Counting practices, creating coiled and tangled boundaries around academic impact, have become a taken-for-granted part of the everydayness of what it means to function at a university.

As Gilles Deleuze (1992) wrote on societies of control, "the brashest rivalry [is constantly presented] as a healthy form of emulation, an excellent motivational force that opposes individuals against one another and runs through each, dividing each within" (p. 5). The coils between university rankings and academic merit or impact has produced a desire for "auditable practices, [that have] turned academics into deindividualised members of an auditable group" (Angervall, 2018, p. 106). Becoming an academic is a process of becoming-countable, becoming domesticated in particular ways, seeking practices of recognition through citation scores, scholarly impact, and legible research trajectories. Numbers, as Deleuze and Félix Guattari (1987) wrote, function with the state to "gain mastery over matter, to control its variations and movements" (p. 389). In the neoliberal university, relationships, and collaborations only matter if they are seen or counted by an algorithm (Monea, 2016) or if they make us more productive academic subjects (Cannon \& Cross, 2020).

Academic subjects, then, are becoming with what John Cheney-Lippold (2011) termed a "new algorithmic identity" through the collection and analysis of scraped and siphoned data (p. 165). Through the counting practices embedded in platforms such as Google Scholar, ResearchGate, and Academia, academic identities become explicitly visible and are measured in relation to the spectre of a 'super scholar;' a production machine whose citation counts and reads are steadily on the rise, who can 
always click the button labelled 'add new research.' The super scholar is simultaneously visible and invisible. It is the motivational force for our emulation, even as it is only a disembodied algorithmic ideal toward which we strive with each click and upload. We are tied to this super scholar through measurement practices that draw lines between past-present-future versions of ourselves-lines that domesticate us, keep us in line, rein us in. The numbered number of the neoliberal academic subject is one of cadence and measure, a tempo keeping us in line (Deleuze \& Guattari, 1987). And yet, the tethers of domesticity in academia are not only cast by external forces, rather, we are implicated in our taming.

\section{Recalculation and Potential}

The algorithms of academic platforms, claiming to measure and increase our impact and create a more transparent academic subject, are constantly recalculating our subjectivities. Cheney-Lippold (2011) described this process as a form of control and discipline, writing, "as more data is received about a certain user's behaviour online, new coded computations can be done to change who the user is believed to be and what content that user might desire... in this constant feedback loop we encounter a form of control" (p. 168). In a double-bind of transparency-recalculation, practices of counting act as systems of control, passcodes that "mark access to information or reject it" (Deleuze, 1992, p. 5). Numbers function as internalised disciplining devices. Data, defined and organised by the algorithms within and outside of the online academic platforms, draw boundaries about what behaviours are valued, as well as how they are defined and can function. Data, then, become a mechanism for cultivating good academic subjects as well as the means by which these subjects are contained.

Data are collected to measure and account for the academic impact of individuals from different fields and disciplines, the differences between individuals are subsumed into computational norms for academic publishing. A pattern emerges as to what is expected from $x$ academic in $x$ field. Deviations, or spikes, from the computational norm are met with fear and resistance (Pasquinelli, 2016). In this form of control, there is modulation and tuning to the computational norm, the ideal of the super scholaraway from the spike, away from deviation. Matteo Pasquinelli offered the spike as a 
potential for "more complex architectures of knowledge" (2016, p. 260). Thus, by leaning into the spike, seeking deviation, one might find wild possibilities away fromand yet still in relation to-the line of control.

Anomalies born out of the norming of diverse data points are one potential for wilding Luciana Parisi (2013) cited another potential in the algorithms themselves. She proposed that algorithms are not inert and docile but are objects that seize and grasp. In other words, algorithms contain within them a feral quality, anomalies, the potential for wilding. Wilding, (de)cultivating, variating, proliferating. An algorithm within these platforms assigns a value to a scholar's impact, there are temporal and qualitative variations that are incomputable. Algorithms, rather than being pure devices of control modulate "like a self-deforming cast that will continuously change from one moment to the other, or like a sieve whose mesh will transmute from point to point" (Deleuze, 1992, p. 4). These variations span from author order and journal reputation within a field to the more affective qualities of collaboration, resonance, or possibility produced through and within the doing of academic work. These and other incomputable data, Parisi (2013) argued, are contagions within computations. Similar to Cheney-Lippold's assertions, the computations, and thus the representations of scholarly impact take on a life of their own, escape domestication. Thus, even as data metrics act on/with us to control and contain our movements in particular ways as academics, they also produce the possibility for other becomings. Reaching into the past and future, the preemptive measurements of impact amount to what Parisi (2013, p. 85) termed "post cybernetic control"-not just tracking movement but generating possibility for future movements and interactions. Therefore, within algorithms there exists the simultaneous potential for control/domestication and possibility/wilding through recalculation. The space between control/possibility and domestication/wildness is what we aim to explore and make kin with through this paper. There are, we argue, possibilities in the computational contagions that allow for wild possibilities and potentials.

\section{Becoming with Counting Logics}

The neoliberal logics that are enmeshed in counting practices and platforms seep and creep into our various material becomings. We, the authors, and perhaps other 
academics, continue to comply, continue to be pulled by the numbers, the counting. We are pulled to perform in relation to the number, to be counted, to count. And yet, we resist the one-way pull to be domesticated, to be docile. Our academic bodies become monstrous as we paradoxically mutate, simultaneously seeking resistance to and visibility within the neoliberal university. We are beyond and outside ourselves, and through leaning into the contagion in the platforms, we become differently.

We have witnessed how these counting practices shield from view and minimise the visibility of the concrete labour, the day to day-ness of student meetings and relationships with colleagues and reading groups (Caddell \& Wilder, 2018; Flint \& Guyotte, 2019; Hepler et al., 2019; Nxumalo et al., 2020). In research meetings, we calculate how a potential publication might count or not before we have even begun the writing. Futures are foreclosed by a speculative accounting and attention to the production of our academic subjects in line with that (and other futures) (Myers, Cannon \& Bridges-Rhoads, 2017). To be clear, the authors are not opposed to the use or consideration of numbers or counting practices altogether-we are not opposed to some cultivation. However, we wonder how particular practices of domestication become dangerous and foreclose possibility in the academy, and how, we might cultivate other (wilder) possibilities of becoming academic. In the following section, we seek to consider how data/numbers are "inserted into specific assemblages and what is expressed through this operation" (Sellar \& Thompson, 2016, p. 500). We wonder, how are we becoming with particular counting practices? How do counts inform our ways of relating in the academy even as we consider resisting them?

\section{Wild Possibilities through Nomadic Ethics and Apparatus}

As we consider how our past/present/future academic subjectivities are modelled and predicted, we think the algorithms in relation to feminist new materialist philosophers, Braidotti and Barad. We think counting practices together-apart, wondering, what does it do to think ontologies of number with these theories, what falls apart? What possibilities emerge? We recognise the ways in which we are tied to and bound to our "large object of critique" (Colman, 2020, p. 1) and in response we ask, "what if..." a question that "enables the possibility of finding what will engender better conditions for all forms of life" (p. 17). 
Specifically, we ask what if we take up Braidotti's (2006) ethics of nomadic subjectivity? A nomadic ethics "rejects moral universalism and works towards a different idea of ethical accountability in the sense of a fundamental reconfiguration of our being in a world that is technologically and globally mediated" (p. 15). Nomadic ethics, which builds from Deleuze's immanent relational ontology, envisions an affirmative and non-unitary subject in contradictory social relations, a subject that has the "desire, the ability, and the courage to sustain multiple belongings in a context which celebrates and rewards Sameness and one-way thinking" (Braidotti, 2006, p. 69). What if, we thought algorithms with other multiple belongings? What if, instead of sameness, we sought the spike?

While Braidotti offers the 'what if' of experimentation and proliferation, Barad provides a framework for thinking ourselves together-apart from the numbers and counts that become representative of us. Through her tracing of the philosophy-physics of Niels Bohr, Barad (2007) reconceptualised objectivity and measurement within a posthuman ethico-onto-epistemology. Building on Bohr's indeterminacy principle, she asserted that the properties and boundaries of phenomena only become determinant through intra-actions which "enact agential separability" (Barad, 2007, p. 140). This enacted separability is the cut together-apart. The cut both separates the phenomenon and binds it as a unit. The cut is an ongoing enacted making and remaking of the subject/object, not in any way a permanent cut. Yet, each cut, each measurement, each citation, is reconfiguring the world.

We wonder as part of this work how we might creatively and response-ably be in touch with these measurements and accountability practices differently to create other consequential meanings. Barad (2012) proposed that,

measurement is surely a form of touching [...] a highly developed sense of touch, a feel for the instruments and molecules at hand. ('Good hands,' that's what it's called.) And touch engages us in a felt sense of causality, whether we generally acknowledge that or not, and whatever it is we may think of this charged and highly important term. Touch moves and affects what it effects. ( $p$. 208)

In this (re)search engagement, then, we touch and lean closer to the measurements that we are becoming with as academics. We ask, what if, we experiment with a kind 
of "self-touching:" "an encounter with the infinite alterity of the self" (Barad, 2012, p. 213) that is a doing and undoing of academic identity — simultaneously affirming and making indeterminate-a creating of difference within the strangely familiar. What if we acknowledge how we are in touch with the platforms, the norm and the spike, and the algorithm and its contagion?

\section{Academic Platforms}

We focus our inquiry specifically on the counting practices of the academic networking platforms Academia, ResearchGate, and Google Scholar. Each of these sites offers a way of measuring academic influence or impact-through Google Scholar's H-score, ResearchGate's RG, and Research Interest scores, or through site visits and mentions on Academia. We argue that although the academic subject is (re)produced through the counting practices of ResearchGate, Academia, and Google Scholar, the reproduction is not regular, logical, or well-defined. Rather, it is monstrous, or what Elizabeth de Freitas (2016) described as "machinic but non-axiomatic" (p. 463), and what Deleuze (1992) described as "undulatory, always in orbit, in a continuous network" (p. 6). Weaving together the orientations of nomadic ethics of Braidotti and attention to knowledge-making apparatus of Barad, we began by noticing and collecting the numerous indicators and enticements sent to our inboxes regarding our scholarly 'impact.'

Following Braidotti's urge to decelerate and seek affirmative modes of relating, and layered with Barad's emphasis on attending with response-ability to specific material arrangements of knowledge-making apparatuses, we turn next to Sam Sellar and Greg Thompson's (2016) work to trace the ontological and epistemological assumptions underlying the assemblages of academic research platforms. Given this data, we then retheorise and reimagine how the assemblages would function and warp if we thought the assumptions underlying their form with Braidotti and Barad. Warping and stretching these assumptions, wilding, (de)cultivating what has been taken for granted, allows us to see how the differences in knowledge making practices matter in ethical and material terms. We imagine in excess of the platforms to proliferate reconfigurations of academic subjectivity and measurement. 


\section{Specific Material Arrangements: Givens, Forms, and Expressions}

Similar to Deleuze and Guattari's (1987) assertion that when considering numbers, "the question is not one of good or bad but of specificity" (p. 290), Sellar and Thompson (2016) noted that, "our concern is not with the veracity of data in any particular case, but rather to understand how information ontologies transform data into information, and the implications of this transformation for learning" (p. 495). Sellar and Thompson argued that the assumptions undergirding the givens, forms of content, and expression of information assemblages work in concert to govern and control subjectivities. In what follows, we move within ResearchGate, Google Scholar, and Academia to ask the questions: What are the givens? What are the forms of content? And what are the forms of expression? Through this tracing, we explore the assumptions operating within each of these counting systems before moving through how these assumptions become in conversation with Barad and Braidotti.

\section{Givens}

All three systems rest on the fundamental premise that a scholar's impact can be measured, tracked, and predicted based on interactions with other scholars, including citations, mentions, reads, and downloads. Impact flows from the quantity of these interactions and from their spatiotemporal reach. Impact is put forward as the key given in academia and is assumed to be linearly expandable.

Add new research.

Add your co-authors.

Boost your score.

Add your skills and expertise.

Increase your impact.

These prompts, a small sample of provocations that litter the websites and email notifications generated from the three sites, are based on a premise of givens. This line of thought and assumptions are further laid out by ResearchGate in their description of their presumed cycle of impact: 
When researchers read, recommend, or cite a research item, its Research Interest goes up. Based on our data and feedback from scientists, we chose to focus on these interactions to reflect the lifecycle of a scientist's increasing interest in a piece of research. First, a researcher accesses a research item. If it sounds of interest, they may read the full-text (if it is available). If they like what they read, they might recommend it. And if the work is really relevant, they might cite it in their own research. (ResearchGate A, n. d.)

Thinking with Sellar and Thompson's (2016) interrogation of information ontologies, there are moral givens suggested by these statements-the linear assumption that reputation 'in the hands of researchers,' as Research Gate described it, is a good thing. Simultaneously, there is the assumption that numbers can represent scholarly quality or impact on a field. Further, this indicates that the numbers can become emancipatory in some way, can allow us to prove ourselves. Inherent in this logic is a presumption that impact is out there and measurable. We just need to have the right tools to measure it. We can control our impact through particular actions, through increasing our network.

Track your growing reputation. (Academia)

People are reading your work. (ResearchGate)

2 Days Only, Get 50\% Off Premium: Make the Best of Uncertain Times.

(Academia)

Present in these calls and prompts and notifications is a neoliberal logic of rational choice and free will. If you are a rational academic, you will make good choices and be counted. You will make the best of these uncertain times by purchasing a counting system to help you better track your academic life. The alternative assumption, then, is that if you do not adhere to the counting logics you are irrational, and you will fail, and that the failure would have been preventable. Like most neoliberal logics, this 'choice' is presented and is presumed to be natural and easy, as Google Scholar puts forward,

Google Scholar Metrics provide an easy way for authors to quickly gauge the visibility and influence of recent articles in scholarly publications. Scholar Metrics summarize recent citations to many publications, to help authors as they consider where to publish their new research. (Google Scholar, 2019) 
The logics and counting are presented as helpful and necessary. It is assumed that you desire this counting, that you want to be as counted as possible. Further, the systems also put forward the message that an individual scholar has the agency to increase their impact (or not) through defined and specific actions, like inviting their co-authors and posting links to articles through other networking sites. Yet these forms are controlled and confined: ResearchGate, Google Scholar, and Academia all instruct academics what to do, defining what counts, they domesticate, cultivating particular actions. For example, there is the assumption that older work matters less than newer work (emphasised by the buttons on all three sites urging researchers to 'add new work'), that who reads or engages with your work matters ("The name M. Flint is mentioned by a well-known author on Academia"). It matters who reads your work and where they are from, who desires you and your work.

Get all the tools and information you need to advance your academic career.

We continuously monitor your Mentions and notify you. (Academia)

You may be missing out on more than you realize. (Academia)

\section{Forms of Content}

Sellar and Thompson (2016) described forms of content as "any actions, bodies or things that can be interpreted in standardized ways by information ontologies" (p. 498). Clicking through the back end of ResearchGate, one can find a recipe for a score:

A read* has a weighting of 0.05 .

A full-text read* has a weighting of 0.15 .

A recommendation has a weighting of 0.25 .

A citation has a weighting of 0.5 .

Asterisks and peripheries abound though a reader has to only scroll further to find additional definitions, more boundaries of content. Somehow the value of a citation has been assessed to be worth ten times a read. A read is defined as when "someone views a publication summary or clicks on a figure, whereas a 'full-text read' is counted when someone views or downloads the full-text" (ResearchGate C, n. d.). The site notes that reads by people who are not ResearchGate members do not count, noting 
that "by only measuring interest from scientists that have logged in to ResearchGate, we can provide the 'who' behind the metrics, a key part of understanding how an author's work is being received" (ResearchGate B, n. d.) The standardisation then, defining what 'counts' as content, produces academic bodies that can only be defined in particular ways. Some interactions count more than others, interactions layer, congeal, overlap to produce a scholar visible through the platform, valuableidentifiable through a number or score.

Adding your lab affiliation to your profile will help more researchers in your field connect with your work on ResearchGate.

Your publication has a new achievement. (ResearchGate)

Google Scholar (n. d.) writes that their asterisk indicates that their cited by count includes citations that might not match the article. It is an estimate made automatically by a computer program. They note that you can "check these citations by clicking on the article's title and looking for 'scholarly articles' with a * next to their title" (Google Scholar, n. d.). Algorithms counting and recounting reads and citations have the potential for wildness in the asterisk; potential for variation. And yet, even with-and particularly with-the hedging of the asterisk, the danger in these systems is that they are presumed to be linear and stable, molehills rather than the coils of a snake (Deleuze, 1992). In other words, "only certain aspects of a world are 'sensible' to information ontologies and the algorithms these support" (Sellar \& Thompson, 2016, p. 498). The presence created online is a distortion of our academic subjectivity, a body that both is and is not our self. There is simultaneously a magnification of the importance of our work and at the same time a false narrative of who you are, who you can be. For example, a sample of the daily updates from Academia received by Maureen over the course of a week:

'M Flint:' 34 new mentions, including one in a Microbiology (medical) paper.

'Flint, M:' 5 new mentions, including one in a General Medicine Paper.

The name 'Maureen Flint' has 14 new mentions.

M Flint; Flint, M; Maureen Flint. As a qualitative researcher whose work has centred on higher education contexts and artful methodologies, the likelihood that a paper from general medicine or microbiology might mention this particular configuration of 
Maureen Flint is almost laughable. And yet, there is a push/pull of desire here. What might it do to explore the possibilities of inter/transdisciplinarity that Academia and ResearchGate exuberantly, wildly, monstrously propagate? How might these pushes start lines of inventive connection, practices of (de)cultivation, sparking joy or creativity, or even perplexity in their nonsense? How might we respond to these monstrous, wild, misrecognitions? How might we work against/within it, shifting against the logics of domestication and tameness?

\section{Forms of Expression}

Sellar and Thompson (2016) defined the forms of expression as the "set of rules for converting test-taking and 'learning' into outcomes via the interpretation, analysis and coding of the given data to generate information" (p. 498). Reads and cites and mentions and recommendations congeal to produce a score, a percentage, a count.

People are reading your work. (ResearchGate)

Your weekly stats report is here. (ResearchGate)

All three of the counting systems present graphs, charts, and analytics compiled daily for the desiring academic. In addition to enticing users to compare themselves to others, these graphs tempt the researcher to participate in a form of self-touching and provoke the comparison between past present and foreseeable future selves. Academia's 'impact' page measures unique visitors, downloads, pages read, and views, along with the country, city, research field, job title, traffic source, and university of origin of your engaged readers. These counts are compiled by the minute, in a chart documenting the city and country of origin of your viewer, blurring out some information behind a paywall (upgrade to view). ResearchGate, likewise compiles reads and citations and mentions into a score displayed next to your name, also compiling your stats and scores into graphs and charts, tracking the undulations of citations, recommendations, reads, full-text reads, and research interests on your stats page. Your count is compiled into a single RG score composed of publications, questions, answers, and followers, and an h-index, defined as "an author-level metric that measures your research output and its citation impact. It is based on a set of your most cited work and the number of citations it's received" (ResearchGate C, n. d.). You are placed in a percentile ("Your score is higher than $50 \%$ of all Research Gate 
members' scores") and a helpful box at the top and bottom of the screen beckons you to "Add more research. Boost your scores. Help create more exposure for your work by adding more of your research." Finally, Google Scholar tracks citations over time, a graph charting the number of citations oscillating over time, capped off by a small chart documenting citations, $\mathrm{H}$-index, and $\mathrm{i} 10$-index, "the number of publications with at least 10 citations" (Google Scholar, n. d.).

Forms of expression, counts, scores, stats congeal into charts and graphs and visualisations that (re)present and offer up a snapshot of academic productivityimpact. Measuring is an ethico-onto-epistemological practice, which according to neoliberal logics, helps us stand in the right place and offers the comforting promise of domestication. And yet the ground is not stable; domesticity uncomfortable. The ground begins to quake and crumble upon closer examination. $\mathrm{H}$-indexes differ across sites. Stats and scores vary across fields. Inboxes are flooded with emails about articles presumed to relate to your own. Within these gaps and misrecognitions, there is a possibility to become differently, to orient affirmatively, to disrupt and create lines of inventive connection. Cultivate in excess of docility. In the following section, we return to Braidotti and Barad to explore how we might spark joy or creativity within these counting metrics. We consider how these metrics might create the possibility of perplexity, bewilderment, a productive and generative wildness. As Halberstam (2019) noted of Facebook in relation to friendship, these systems "co-opted" scholarship and "turned it into a vector for capitalization, advertising, and networking" (para 20). In response, we seek ways to produce other vectors, mutations, and detours, cultivating wild becomings.

\section{Proliferating Indeterminacy}

Braidotti (2019) writes that, "situating knowing subjects as immanent to the very conditions they are trying to understand, change, or resist, means that critical thinking is about being able to make a careful ethical distinction between different speeds and territorializations of both knowledge and subject production" (p. 154). We are immanent to, or in Barad's (2007) terms, in intra-action and co-constituting the world with, these counting metrics and academic platforms. And yet, as we have argued through mapping the givens, forms of content, and expression, our academic 
subjectivities already have an air of the monstrous about them, many headed Scylla (H-scores, RG scores, reads, and counts contradicting, proliferating), swirling Charybdis (email pings: people are reading your work, you have a new reader), gatekeeping Sphinx (upgrade to view your mentions), all-seeing Argos and scrying, future peering Centaurs (watch your impact rise).

Thinking these platforms with Barad and Braidotti allows us not just to reject these mythical potentials as bad or good, but to think of them as specific material arrangements co-constituting this thing called impact. Taking up this view, we can return to our 'what ifs'.

\section{What if, Nomadic Subjectivity?}

We asked, what if, we were to take up Braidotti's (2006) ethics of nomadic subjectivity? In order to enact this 'what if' with Braidotti, we take up the following ethical rule that 'to be worthy of our times' we need to change our approach and view historical contradictions "not as some bothersome burden, but rather as the building blocks of a sustainable present and an affirmative and hopeful future, even if this approach requires some drastic changes to our familiar mind-sets and established values" (Braidotti, 2019, p. 3). Inspired by this rule, we approach the project of academic life as an ongoing process, a project of (de)cultivating linear docile practices, spinning web-like and poly-centred potentials, a project of developing a "working hypothesis about the kind of subjects we are becoming" (Braidotti, 2019, p. 2). Braidotti (2019) advocated for the necessity of this approach in light of the exhaustion typifying the present moment, exhaustion which is surely increasing in the midst of this COVID-19 here/now. More specifically, Braidotti has recommended practices of experimentation such as: cultivating deceleration, honouring complexity, and seeking ways to "rework together the negative experiences and affects that enclose us" (Braidotti, 2019, p. 169). These are not new calls to action as they make lines to Guattari's (2000) call for a praxic opening-out that is "precarious, finite, finitized, singular, singularized, capable of bifurcating into stratified and deathly repetitions or of opening up processually from a praxis that enables it to be made 'habitable' by a human project" (p. 53). A process of experimentation seeks (de)cultivation, unlearning that which has become sedimented in our being - an orientation to the wild potentials of algorithms. 
All these platforms map who and where and how many but miss the momentum, potential affect, forces, flows - becoming wild(er)ness. As Braidotti (2019) wrote, "we have to learn to think differently about ourselves" (p. 166) and "every present event contains within it the potential for being overcome and overtaken; its negative charge can be transposed" (p. 167). Indeed, mythology is replete with tales of hero(in)es outwitting monsters, taming them, subverting the wild(er)ness to their will. Rather than accept this historical (and often patriarchal) legacy of the duality of good/evil, human/monster, wild/tame, we rather seek to embrace our response-ability to the monstrous. In other words, we are discontent to either uncritically be tamed by these systems, or to reject them all together.

Through the practice of continually locating ourselves as entangled with, producing, and produced by these metrics, pulling apart the givens, content, and forms of expression, we are unfolding the taken for granted assumptions of counting practices. This is a qualitatively different type of positioning, a different relation to the monstrous that is no longer about these measurements as static, as a status, something to be achieved or overcome, but about becoming and momentum. Braidotti (2006) described nomadic ethics as a,

choice in favor of the richness of the possible, an ethics and politics of the virtual that decorporealizes and deterritorializes contingency, linear causality and the pressure of circumstances and significations which besiege us. It is a choice for processuality, irreversibility, and resingularisation (p. 127).

With Braidotti, we can imagine the RG score as a vector into possibility; an invitation to wildly zigzag across multiple time zones, pinging and mentioning and citing across fields and disciplines, invoking a spirit of transdisciplinarity. The information ontologies of ResearchGate become an entry point for resistance; an affirmative politics of location that embraces asymmetrical starting locations and an affirmative ethical scholarly practice. Braidotti invites us to consider our citation and clicking practices as ethical moves. Our relations matter. Our clicks matter, producing academic bodies through the twitch of a finger. With Braidotti, these embodied movements are not a one-way linear causality, but a relational zigzagging between bodies and subjectivities that makes possible previously unforeseen resistances to logics of control and possibilities to become otherwise. 


\section{What if? A Cut Together-Apart}

With Barad, we asked, what if we acknowledge how we are in touch with the platforms, the norm and the spike, the algorithm and its contagion? All measurements whether qualitative or quantitative involve a particular choice of apparatus that provides the "conditions necessary to give meaning to a particular set of variables, thereby placing a particular embodied cut between the object and the agencies of observation" (Barad 2007 , p. 115). The concept of scholarly impact, in particular, is produced through the specific material arrangements of academic platforms, academic subjects, journal editors, universities, and on and on. A cut is being made and remade as to what impact is and how it matters. The platforms produce impact as countable, traceable and determined by geographic reach (across universities and countries and regions) and quantity of touches (downloads, cites, mentions). This specific material arrangement of impact forecloses the complementary conceptual becoming of impact. This complementary impact might be measured (though we are not suggesting this attempt) in shifts in thinking, reconceptualisation of concepts, sighs, tears, smiles, and the like and unlike. The specific material arrangements that produce and value the version of impact produced in intra-action with these platforms (determined by geographic reach and citation counts), also foreclose or make more obscure subjectivities that seek to be in relation with, to touch, the complementary concepts to impact.

\section{Wild Shifts}

We find that to affirmatively and joyfully invite this kind of indeterminacy invokes shifts in ways of living and thinking. Barad (2012) wrote that,

we cannot block out the irrationality, the perversity, the madness we fear in the hopes of a more orderly world. But this does not mitigate our responsibility. On the contrary, it is what makes it possible. Indeterminacy is not a lack, a loss, about an affirmation, a celebration of the plentitude of nothingness (p. 218).

By asking 'what if?,' we invite provocations to engender other more response-able forms of life. How might we organise ourselves with these platforms in other specific material arrangements that might privilege complementary givens that bear other 
forms of content and expressions as recognisable? We wonder how we might work our desire wildly, leaning into the siren calls and removing the wax from our ears. If measurement is a form of touching, we are acknowledging the contacts the material appendages to our academic subjectivity. We are becoming with this version of impact. And there is potential and hope in the indeterminacy and contagion within the algorithm, in the idea that (as Barad [2007] described), that a bit of smoke from a cigar might change the specific material arrangements enough for us to catch a glimpse of another version. Indeed, as Barad (2012) wrote-

life, whether organic or inorganic, animate, or inanimate, is not an unfolding algorithm. Electrons, molecules, brittlestars, jellyfish, coral reefs, dogs, rocks, icebergs, plants, asteroids, snowflakes, and bees stray from all calculable paths, making leaps here and there, or rather making here and there from leaps, shifting familiarly patterned practices, testing the waters of what might yet be/have been/could still have been through doing thought experiments with their very being. (p. 207-208)

These shifts from the familiar require an ongoing response-ability to the world's becoming, they demand a departure from our inherited ways of thinking. So, we ask, what do we mean or want to mean by impact? What are the conditions for the meaningful use of this concept? How might we make it/ourselves intelligible differently? What complementary concepts are being left out? Barad (2010) asserted that "every concept is haunted by its mutually constituted excluded other" (p. 253). We intend to look for those hauntings, to seek other spacetimematterings, not to be disturbed but to be made together differently.

Interrogating the assumptions and logics of control producing academic subjectivities with philosophers such as Barad and Braidotti demands ontological and epistemological considerations of the ethical and material cuts we make as scholars. Though ResearchGate, Academia, and Google Scholar claim to measure a scholar's impact, or influence on the field, we find this idea untenable. Research happens in intra-action, is on the move, and is always in excess. The possibilities of a researcher's work will always remain ungraspable, untameable by an algorithm or metric. And yet, these metrics persist, they matter, they work on our bodies. Acknowledging this, we have begun to seek and affirm other ways of being in the academy. Exploring the 
information ontologies at work through multiple philosophical frameworks creates the possibility to produce and create subjectivities that did not "desire commensurability and efficiency according to a model of [scholarship] as representation" (Sellar \& Thompson, 2016, p. 499). Unchecked and unchallenged we believe that information ontologies that privilege counts and categories are a threat to scholarship that has "the sense of an unpredictable and creative adventure of thought" (p. 499). We turn to Deleuze (1992) and Guattari (2000) to "invent other contracts of citizenship" in the academy that "enable the singular, the exceptional, the rare, to coexist with a State structure that is the least burdensome possible" (Guattari, 2000, p. 51).

We are looking for possibilities within the measurement of our academic subjectivities that are fundamentally unpredictable and uncontainable. This is not a rejection of measuring or numbers outright, but rather, a move to imagine numbers differently. As Barad (2012) noted as well, "it may well be the inhuman, the insensible, the irrational, the unfathomable, and the incalculable that will help us face the depths of what responsibility entails" (p. 218). Perhaps, then, we can become measuring monsters, reconstituting, and distorting measurement and challenging the information ontologies toward other ethico-onto-epistemological priorities. Waking ourselves up to more intimate modes of being, derived from a radical reconsideration that seeks to "counter the pervasive atmosphere of dullness and passivity" (Guattari, 2000, p. 69). We will seek the spike, follow the contagion, and explore wild possibilities.

\section{Bibliography}

Angervall, Petra (2018). The academic career: A study of subjectivity, gender and movement among women university lecturers. Gender and Education, 30(1), 105-118. https://doi.org/10.1080/09540253.2016.1184234.

Barad, Karen (2007). Meeting the universe halfway: Quantum physics and the entanglement of matter and meaning. Duke University Press.

Barad, Karen (2010). Quantum entanglements and hauntological relations of inheritance: Dis/continuities, spacetime enfoldings, and justice-to-come. Derrida Today, 3(2), 240-268. https://doi.org//10.3366/E1754850010000813.

Barad, Karen (2012). On touching - The inhuman that therefore I am. differences, 33(3), 206-223. https://doi.org/10.1215/10407391-1892943. 
Barad, Karen (2014). Diffracting diffraction: Cutting together-apart. Parallax, 20(3), 168-187. https://doi.org/10.1080/13534645.2014.927623.

Barbour, Kim, \& Marshall, David (2012). The academic online: Constructing persona through the World Wide Web. First Monday, 17(9), 7-7.

https://doi.org/10.5210/fm.v0i0.3969.

Braidotti, Rosi (2006). Transpositions: On nomadic ethics. Polity Press.

Braidotti, Rosi (2013). Nomadic ethics. Deleuze Studies, 7(3), 342-359. https://doi.org/10.3366/dls.2013.0116.

Braidotti, Rosi (2019). Posthuman knowledge. Polity Press.

Caddell, Martha, \& Wilder, Kimberly (2018). Seeking compassion in the measured university: Generosity, collegiality and competition in academic practice. Journal of Perspectives in Applied Academic Practice, 6(3), 14-23.

https://doi.org/10.14297/jpaap.v6i3.384.

Cannon, Susan O. \& Cross, Stephanie B. (2020). Writing excess: Theoretical waste, responsibility, and post qualitative inquiry. Taboo: The Journal of Culture \& Education, 19(3), 89-112. https://digitalscholarship.unlv.edu/taboo/vol19/iss3/7.

Cannon, Susan O. \& Flint, Maureen A. (in press). Drift and desire: Defamiliarizing Academic Subjectivities. Inscriptions. 4(1), 89.

Cannella, Gaile S., Perez, Michelle S., \& Pasque, Penny A. (Eds.). (2015). Critical qualitative inquiry: Foundations and futures. Left Coast Press.

Cheney-Lippold, John (2011). A new algorithmic identity soft bio-politics and the modulation of control. Theory, Culture \& Society, 28(6), 164-181. https://doi.org/10.1177/0263276411424420.

Colman, Felicity (2020). Feminising politics: Notes on material and temporal feminist modal logics in action. Matter: Journal of New Materialist Research, 1, 1-22. https://doi.org/10.1344/jnmr.v1i1.29895.

de Freitas, Elizabeth (2016). Calculating matter and recombinant subjects: The infinitesimal and the fractal fold. Cultural Studies $\leftrightarrow$ Critical Methodologies, 16(5), 462-470. https://doi.org/10.1177/1532708616655764.

Deleuze, Gilles (1992). Postscript on the societies of control. October, 59(Winter), 37. https://www.jstor.org/stable/778828.

Deleuze, Gilles, \& Guattari, Félix (1987). A thousand plateaus: Capitalism and schizophrenia. (B. Massumi, Trans.). University of Minnesota Press. Originally published in French in 1980. 
Dixon-Román, Ezekiel J. (2016). Algo-Ritmo: More-than-human performative acts and the racializing assemblages of algorithmic architectures. Cultural Studies $\leftrightarrow$ Critical Methodologies, 16(5), 482-490. https://doi.org/10.1177/1532708616655769.

Flint, Maureen A., \& Guyotte, Kelly W. (2019). Pedagogies of the minor gesture: Artful mentorship in college teaching. Visual Inquiry, 8(1), 63-75. https://doi.org/info:doi/10.1386/vi.8.1.63 1.

Google Scholar (2019). Google scholar metrics.

https://scholar.google.com/intl/en/scholar/metrics.html.

Google Scholar (n. d.) Google scholar citations.

https://scholar.google.com/intl/en/scholar/citations.html\#setup.

Guattari, Félix (2000). The three ecologies. (I. Pindar \& P. Sutton, Trans.). The Athlone Press. Originally published in French in 1989.

Halberstam, Jack (2019, February 25). Strategy of wildness. Critique \& Praxis, 13(13). http://blogs.law.columbia.edu/praxis1313/iack-halberstam-strategy-of-wildness/.

Haraway, Donna J. (2016). Staying with the trouble: Making kin in the Chthulucene. Duke University Press.

Hepler, Sarah, Cannon, Susan O., Hartnett, Courtney, \& Peitso-Holbrook, Teri (2019). Undoing and doing-with: Practices of diffractive reading and writing in higher education. In Carol A. Taylor \& Annouchka Bayley (Eds.), Posthumanism and higher education: Reimagining pedagogy, practice and research (pp. 141-151). Palgrave.

Koro-Ljungberg, Mirka (2015). Reconceptualizing qualitative research: Methodologies without methodology. SAGE Publications, Inc.

Martin, Aryn, \& Lynch, Michael (2009). Counting things and people: The practices and politics of counting. Society for the Study of Social Problems, 56(2), 243-266.

https://doi.org/10.1525/sp.2009.56.2.243.

Monea, Alexander (2016). The graphing of difference: Mediation and the case of the knowledge graph. Cultural Studies $\leftrightarrow$ Critical Methodologies, 16(5), 452-461.

https://doi.org/10.1177/1532708616655763.

Myers, Kayla D., Cannon, Susan O., \& Bridges-Rhoads, Sarah C. (2017). Math is in the title: (Un)learning the subject in educational research. International Review of Qualitative Research, 10(3), 309-326. https://doi.org/10.1525/irqr.2017.10.3.309.

Nxumalo, Fikile, Cook, Courtney, Cira Rubin, Jessica, Hendrix Soto, Aimee, Cedillo, Stacia, \& Scott, Michael (2020). Staying with the trouble: Grapplings with the morethan-human in a qualitative inquiry course. Qualitative Inquiry, 26(1), 24-35. https://doi.org/10.1177/1077800419868505.

Parisi, Luciana (2013). Contagious architecture: Computation, aesthetics, and space. The MIT Press. 
Pasquinelli, Matteo (2016). The spike: On the growth and form of pattern police. In Stephanie Hankey, Marek Tuszynski, \& Anselm Franke (Eds.), Nervous Systems (pp. 245-260). KW/Spector.

ResearchGate A (n. d.). Help center: Research interest. https://explore.researchgate.net/display/support/Research+Interest.

ResearchGate B (n. d.). Help center: RG Score: H-score. https://explore.researchgate.net/display/support/h-index.

ResearchGate C (n. d.). Help center: Stats: Reads. https://explore.researchgate.net/display/support/Reads.

Roulston, Kathryn, \& Bhattacharya, Kakali (2018). Teaching qualitative inquiry in the era of the Big Tent: Presenting proliferation and polyphony. International Review of Qualitative Research, 11(3), 251-255. https://doi.org/10.1525/irar.2018.11.3.251.

Sellar, Sam \& Thompson, Greg (2016). The becoming-statistic: Information ontologies and computerized adaptive testing in education. Cultural Studies $\leftrightarrow$ Critical Methodologies, 16(5), 491-501. https://doi.org/10.1177/1532708616655770.

St. Pierre, Elizabeth A. (2014). A brief and personal history of post qualitative research: Toward 'Post Inquiry.' Journal of Curriculum Theorizing, 30(2), 2-19.

Sweet, Joseph D., Nurminen, Emppu, \& Koro-Ljungberg, Mirka (2019). Becoming research with shadow work: Combining artful inquiry with research-creation. Qualitative Inquiry. Advance online publication. https://doi.org/10.1177\%2F1077800419857764.

\section{Author Information}

\section{Susan Ophelia Cannon (cannon so@mercer.edu)}

Susan Ophelia Cannon is an Assistant Professor of Education at Mercer University. She works and thinks across the boundaries of mathematics and statistics education, qualitative inquiry, and teacher education.

\section{Maureen A. Flint (maureen.flint@uga.edu)}

Maureen A. Flint is Assistant Professor in Qualitative Research at the University of Georgia. Her scholarship braids together her interests in the theory, practice, and pedagogy of qualitative methodologies, artful approaches inquiry, and questions of social (in)justice, ethics, and equity in higher education spaces. 